\title{
Notas, novos registros e novas espécies da coleção de Cerambycidae (Coleoptera) do Instituto Nacional de Pesquisas da Amazônia, Manaus
}

\author{
Maria Helena M. Galileo ${ }^{1,3}$ \& Ubirajara R. Martins ${ }^{2,3}$
}

\author{
'Museu de Zoologia, Universidade de São Paulo. Caixa Postal 42494, 04218-970 São Paulo-SP, Brasil. urmsouza@usp.br \\ ${ }^{2}$ Museu de Ciências Naturais, Fundação Zoobotânica do Rio Grande do Sul. Caixa Postal 1188, 90001-970 Porto Alegre-RS, Brasil. \\ galileo@fzb.rs.gov.br \\ ${ }^{3}$ Pesquisador do CNPq.
}

\begin{abstract}
Notes, new records and new species of the collection of Cerambycidae (Coleoptera) of the Instituto Nacional de Pesquisas da Amazônia, Manaus. Four new species described from Amazonian Brazil in Ibidionini: Compsibidion uniforme sp. nov. (Amazonas); Heterachthes rafaeli sp. nov. (Amazonas); in Apomecynini: Amphicnaeia lineolata sp. nov. (Pará); in Desmiphorini: Cotycicuiara magnifica sp. nov. (Amazonas). New records and notes are presented to: Gnomidolon insulicola Bates, 1885 and $G$. lansbergei (Thomson, 1867) (Hexoplonini); Desmiphora (D.) uniformis Galileo \& Martins, 2003 (Desmiphorini), Omosarotes paradoxum (Tippmann, 1955) (Cyrtinini) and Ozotroctes ogeri Tavakilian \& Néouze, 2007 (Acanthoderini).
\end{abstract}

KEYWORDS. Brazilian Amazon; Neotropical; new records; new taxa; taxonomy.

RESUMO. Espécies novas descritas da Amazônia brasileira em Ibidionini: Compsibidion uniforme sp. nov. (Amazonas); Heterachthes rafaeli sp. nov. (Amazonas); em Apomecynini: Amphicnaeia lineolata sp. nov. (Pará); em Desmiphorini: Cotycicuiara magnifica sp. nov. (Amazonas). Novos registros e notas são apresentados para: Gnomidolon insulicola Bates, 1885 e G. lansbergei (Thomson, 1867) (Hexoplonini); Desmiphora (D.) uniformis Galileo \& Martins, 2003 (Desmiphorini); Omosarotes paradoxum (Tippmann, 1955) (Cyrtinini) e Ozotroctes ogeri Tavakilian \& Néouze, 2007 (Acanthoderini).

PALAVRAS-CHAVE. Amazônia brasileira; Neotropical; novos táxons; novos registros; taxonomia.

Em maio de 2010, visitamos a coleção de cerambicídeos do Instituto Nacional de Pesquisas da Amazônia, em Manaus, e retiramos exemplares para estudo que resultaram três observações sobre espécies descritas e descrição de cinco novas espécies. Nessa visita fomos acolhidos por José Albertino Rafael e por Augusto Henriques, curador da coleção.

Na subfamília Cerambycinae, a tribo Hexoplonini, revista por Martins (2006), apresentamos novos registros e comentários sobre Gnomidolon insulicola Bates, 1885 e $G$. lansbergei (Thomson, 1867). A tribo Ibidionini foi estudada, respectivamente, por Martins \& Galileo (2007) e por Martins (2009). Descrevemos duas espécies, uma em Compsibidion Thomson, 1864 outra em Heterachthes Newman, 1840.

Em Lamiinae, descrevemos três novas espécies. Em Apomecynini, publicamos uma espécie inédita em Amphicnaeia Bates, 1866, gênero com 29 espécies de pequenas dimensões (4-6 mm de comprimento) que ocorre nas Américas Central e do Sul.

Em Desmiphorini, além de apresentarmos para Desmiphora (D.) uniformis Galileo \& Martins, 2003, novos caracteres, a figuramos a cores para subsidiar a ilustração original cuja reprodução não é muito fiel. Descrevemos também uma nova espécie em Cotycicuiara Galileo \& Martins, 2008. Esse gênero foi descrito para conter seis espécies da América do Sul (Galileo \& Martins 2008). Mais cinco espécies foram incluídas por Martins \& Galileo (2010) e uma chave atualizada para identificação das 11 espécies. Descrevemos agora a décima segunda espécie de Cotycicuiara.

Em Cyrtinini e Acanthoderini, apresentamos novos registros.

As siglas citadas no texto correspondem a INPA, Instituto Nacional de Pesquisas da Amazônia, Manaus; MZSP, Museu de Zoologia da Universidade de São Paulo, São Paulo.

\section{Cerambycinae \\ Hexoplonini \\ Gnomidolon insulicola Bates, 1885}

Gnomidolon insulicola Bates, 1885: 260; Martins 1967: 245 (sin.), 1971a: 1429, 1971b: 128; Joly 1991: 21; Chemsak et al. 1992: 50 (cat.); Martins 2006: 148 .

Gnomidolon elegantulum; Aurivillius 1900: 410 non G. elegantulum Lameere, 1884.

Gnomidolon piceicollis Linsley, 1935: 481; Martins 1967: 245 (sin.)

Gnomidolon seabrai Martins, 1960: 2; 1967: 245 (sin.).

Gnomidolon insulicola é espécie extremamente variável e a forma que descrevemos, a seguir, corresponde a ilustrada por Martins (2006: 149, fig. 156). Esta forma paraense difere da venezuelana por apresentar os metafêmures amarelados no pedúnculo e na extremidade e, no centro, castanho-amarelado. A cabeça e o protórax são como na forma seabrai; o padrão de colorido elitral e o espinho externo da ponta dos élitros são como na forma venezuelana. A forma paraense é descrita: 
Cabeça preto-avermelhada. Escapo vermelho-alaranjado. Pedicelo e flagelômeros amarelados.

Protórax preto-avermelhado. Escutelo revestido por pubescência esbranquiçada. Esternos mesotorácicos avermelhados, pubescentes. Metasterno castanho-avermelhado com pubescência látero-anterior e látero-posterior.

Cada élitro com faixa acastanhada que se inicia junto ao escutelo, sem atingir o úmero, segue pela sutura até o terço anterior, onde se volta obliquamente para a margem; região entre esta faixa e a margem levemente alaranjada no úmero e esbranquiçada no restante; faixa branca, larga, oblíqua atrás do meio; terço apical alaranjado anteriormente e gradualmente mais claro para a extremidade que é branca, transparente. Ápice dos élitros transversalmente truncado com espinho curto, externo.

Mesofêmures amarelados; metafêmures amarelados no pedúnculo e na extremidade e, no centro, castanho-amarelado. Metafêmures com espinho externo. Tíbias e tarsos amarelados. Urosternitos alaranjados.

Dimensões em mm. Comprimento total, 6,5; comprimento do protórax, 1,6; maior largura do protórax, 0,9; comprimento do élitro, 4,4; largura umeral, 1,3.

Material examinado. BRASIL, Pará: Óbidos (Fazenda Pajurá, 1'37'21'S, 55²3'14'W), fêmea, 5-11.IX.2001, J. A. Rafael \& J. F. Vidal col. (INPA).

\section{Gnomidolon lansbergei (Thomson, 1867)}

Octoplon lansbergei Thomson, 1867: 159.

Octoplon landsbergi; Aurivillius 1912: 107 (cat.).

Gnomidolon lansbergei; Martins 1967: 218; Monné 2005: 311 (cat.).

A espécie foi descrita originalmente da Venezuela. Joly (1991) registrou para Venezuela, Distrito Federal: Chichirivique (litoral) e Anzoátegui: Clarines. Assinalamos a espécie para o Brasil.

Material-examinado. BRASIL, Amazonas: Manaus (Rio Solimões, Lago do José), macho, 9.VIII, sem coletor (INPA).

\section{Ibidionini}

\section{Compsibidion uniforme sp. nov.}

(Fig. 1)

Etimologia. Latim, uniformis = uniforme, alusivo ao colorido corporal.

Fêmea. Cabeça avermelhada, brilhante. Lobos oculares superiores com três fileiras de omatídios. Tão distantes entre si quanto o quádruplo da largura de um lobo. Tubérculos anteníferos projetados. Vértice brilhante, com pontos muito esparsos. Antenas pretas, tão longas quanto o corpo. Antenômero III carenado. Protórax avermelhado. Pronoto brilhante, praticamente sem pontos, sem tubérculos, com pubescência serícea, esbranquiçada, restrita ao adelgaçamento basal. Partes laterais do protórax como o pronoto. Prosterno com duas faixas paralelas de pubescência serícea esbranquiçada. Escutelo revestido por pubescência serícea esbranquiçada.
Élitros avermelhados com o extremo apical preto; três fileiras dorsais de pontos pilíferos; extremidades obliquamente truncadas e desarmadas. Pernas pretas. Fêmures com pubescência esbranquiçada, esparsa. Esternos torácicos finamente pubescentes menos no centro do metasterno. Urosternitos brilhantes, avermelhados, exceto o V, preto.

Dimensões em mm. Comprimento total, 8,2-8,1; comprimento do protórax, 2,2-2,2; maior largura do protórax, 1,21,2; comprimento do élitro, 5,2-5,2; largura umeral, 1,5-1,6.

Material-tipo. Holótipo fêmea, BRASIL, Amazonas: Maués (Rio Abacaxis, Campina Capamiri, 4³5'49’S, 58¹3'14’W), 31.V.2008, J. A. Rafael \& equipe col., armadilha luminosa (INPA). Parátipo fêmea, Brasil, Rondônia: Guaporé (12¹3'95'S, 60³2'44'W), 23.IV.2008, J. A. Rafael \& F. F. Xavier Filho col., armadilha luminosa (MZSP).

Discussão. Na chave para espécies de Compsibidion, Martins \& Galileo (2007) separaram as espécies de Compsibidion que apresentam olhos com três fileiras de omatídios. Compsibidion uniforme sp. nov. distingue-se de todas as espécies desse grupo pelas faixas paralelas de pubescência serícea no prosterno. A espécie amazônica desse grupo, $C$. sphaeriinum (Bates, 1870), tem os ápices elitrais biespinhosos e pontuação elitral de interestrias, além dos pontos pilíferos. Martins \& Galileo (2007) acrescentaram que o pronoto tem pubescência em toda a superfície, menos numa faixa longitudinal estreita no meio da metade anterior. Compsibidion uniforme tem os ápices elitrais desarmados e o dorso de cada élitro, apresenta três fileiras de pontos pilíferos.

\section{Heterachthes rafaeli sp. nov.}

(Fig. 2)

Etimologia. O epíteto é uma homenagem a José Albertino Rafael, um dos coletores do holótipo.

Cabeça castanho-avermelhada. Vértice esparsamente pubescente (32X). Região entre os tubérculos anteníferos com pontos finos. Lobos oculares superiores com quatro fileiras de omatídios. Tubérculos anteníferos aguçados. Antenas alaranjadas atingem o ápice elitral no terço apical do antenômero VII. Escapo cilíndrico. Antenômeros III a V engrossados nas antenas dos machos.

Protórax castanho-avermelhado. Pronoto com pubescência esbranquiçada, esparsa (20x), menos ao redor do tubérculo central. Pronoto com o tubérculo central mais aparente e os ântero-laterais e os póstero-laterais apenas indicados. Partes laterais do protórax com pubescência amarelada, muito esparsa, organizada em duas faixas longitudinais mais compactas no limite com o prosterno. Prosterno brilhante. Esternos torácicos avermelhados e finamente pubescentes. Escutelo cobertos por pubescência acinzentada.

Élitros castanho-escuros; grande mancha lateral amarelo-esbranquiçada, que não toca a declividade basal nem a sutura e quase atinge o meio. No terço apical, faixa amareloesbranquiçada, oblíqua em sentido ascendente da margem para sutura e mais larga na margem do que na sutura. Imediatamente atrás dessa faixa, estreita faixa acastanhada, oblí- 

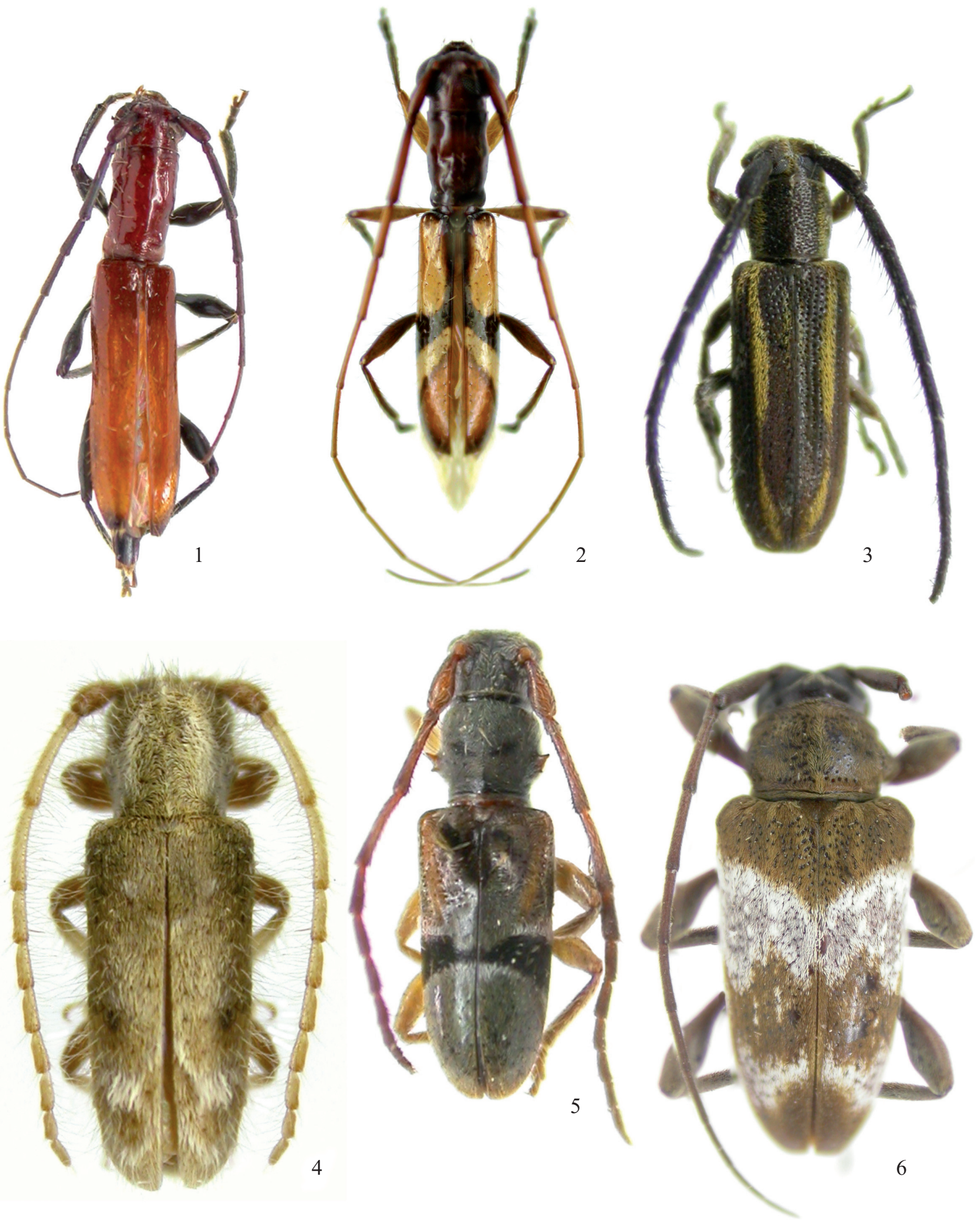

Figs.1-6. 1, Compsibidion uniforme sp. nov., holótipo fêmea, comprimento, $8,2 \mathrm{~mm} ; 2$, Heterachthes rafaeli sp. nov., holótipo macho, comprimento, 10,0 mm; 3, Amphicnaeia lineolata sp. nov., holótipo fêmea, comprimento, 5,3 mm; 4, Desmiphora (D.) uniformis Galileo \& Martins, 2003, macho, comprimento, $6,7 \mathrm{~mm} ; 5$, Omosarotes paradoxum, fêmea, comprimento, 5,5 mm; 6, Cotycicuiara magnifica sp. nov., holótipo macho, comprimento, 11,8 mm. 
qua, da sutura para a margem e que se prolonga pela margem até o ápice; região envolvida por esta faixa, avermelhada. Extremidade elitral com dois espinhos: um curto, sutural, com metade do comprimento do espinho externo. (Élitro direito reconstituído no 'photoshop').

Pro- e mesofêmures alaranjados; metafêmures levemente mais acastanhados. Tíbias acastanhadas. Urosternitos avermelhados.

Dimensões em mm. Comprimento total, 10,0; comprimento do protórax, 2,2; maior largura do protórax, 1,5; comprimento do élitro, 6,4; largura umeral, 2,0.

Material-tipo. Holótipo macho, BRASIL, Amazonas: Presidente Figueiredo (Rodovia 240, km 24, ramal São Francisco), 29-31.X.2008, J. A. Rafael, F. F. Xavier Filho, G. Lourido, R. J. P. Machado \& F. Amat col., armadilha luz, solo (INPA).

Discussão. O padrão de colorido de Heterachthes rafaeli sp. nov. é semelhante ao de $H$. lateralis Martins, 1962, $H$. fascinatus Martins, 1971 e H. pelonioides (Thomson, 1867). Em todas essas espécies os ápices dos élitros são ocupados por faixa esbranquiçada e as antenas dos machos têm os artículos III a VI engrossados.

Em $H$. rafaeli, o ápice dos élitros não tem faixa esbranquiçada e os antenômeros III a V são engrossados. Em $H$. symbolus Martins, 1970, os ápices dos élitros não têm faixa esbranquiçada como em $H$. rafaeli, mas as antenas dos machos têm os antenômeros III-VI engrossados e o padrão de colorido dos élitros é diferente.

\section{Lamiinae Apomecynini Amphicnaeia lineolata sp. nov.}

(Fig. 3)

Etimologia. Latim, lineolatus $=$ diminutivo de lineatus, marcado com linhas.

Cabeça acastanhada. Fronte pontuada $(25 \mathrm{x})$. Vértice com pubescência amarelada. Lobos oculares superiores com seis fileiras de omatídios. Distância entre os lobos oculares superiores menor que a largura de um lobo. Lobos oculares inferiores bem projetados; comprimento pouco menor que a gena. Antenas pretas, unicolores. Antenômero III apenas mais curto do que o escapo e mais curto do que o IV.

Protórax acastanhado; sem espículo lateral. Pronoto sem faixa de pubescência longitudinal central; uma faixa a cada lado de pubescência amarelada; quatro sencilas longas no lado externo das faixas amareladas. Pontuação pronotal relativamente densa (32x). Escutelo com pubescência acastanhada. Lados do metasterno com pontos grandes esparsos

Élitros com tegumento castanho-escuro, revestidos por pubescência acobreada, mais evidente nas partes laterais da metade posterior. Declividade basal dos élitros coberta por pubescência amarelada que emite duas faixas: a mais externa, muito curta e, a mais interna, percorre quase toda a extensão do élitro, mais estreitada no terço apical. Faixa longitudinal de pubescência amarelada, muito esparsa, pouco notável, soldada à sutura, do quinto basal até pouco antes do meio do élitro. Sob os úmeros curta faixa de pubescência amarelada.

Pernas com tegumento acastanhado; pubescência amarelo-esbranquiçada rala.

Urosternitos cobertos por pubescência amarelo-esbranquiçada, adensada nos lados.

Dimensões em mm. Comprimento total, 5,3; comprimento do protórax, 1,0; maior largura do protórax, 1,1, comprimento do élitro, 3,8; largura umeral, 1,5.

Material-tipo. Holótipo fêmea, BRASIL, Pará: Óbidos (Colônia São Tomé). 1-11.IX.2001, J. A. Rafael \& J. F. Vidal col., Malaise (INPA).

Discussão. Amphicnaeia lineolata sp. nov. difere de $A$. piriana Martins \& Galileo, 2001, descrita da Venezuela, pela ausência de faixa amarelada na declividade lateral dos élitros e pela faixa dorsal dos élitros da base ao ápice; pela pubescência elitral com reflexos acobreados. Em $A$. piriana a declividade lateral dos élitros apresenta faixa de pubescência amarelada e a faixa dorsal termina no terço apical e a pubescência elitral não é acobreada.

Difere de A. zonata Martins \& Galileo, 2001, também da Venezuela, pela ausência de faixa amarelada, longitudinal no centro do pronoto, pela ausência de faixa amarelada junto às margens elitrais. Em A. zonata, o pronoto tem faixa amarelada centro-longitudinal e as margens elitrais são percorridas por faixa de pubescência amarelada.

\section{Desmiphorini}

Desmiphora (D.) uniformis Galileo \& Martins, 2003

(Fig. 4)

Desmiphora (D.) uniformis Galileo \& Martins, 2003: 164.

Descrita com base no holótipo fêmea, procedente da Bahia (Maracás), em mal estado de conservação. Um segundo exemplar, também coletado na Bahia permite clarificar e acrescentar novos caracteres.

Cabeça castanho-avermelhada revestida por pilosidade amarelada; vértice com pincel ralo de pelos longos, pretos. Escapo castanho-avermelhado; flagelômeros amarelados e borda apical acastanhada.

Protórax castanho-avermelhado revestido por pubescência amarelada. Pronoto com tufo ralo de pelos brancos e pretos junto à borda anterior; lados com faixa de pubescência esbranquiçada, compacta, mais alargada no meio e oblíqua anteriormente com tufo de pelos brancos, próximo ao tufo da margem anterior. Não apresenta áreas glabras na base. Lados do protórax com pontos glabros, alinhados longitudinalmente, junto á faixa de pubescência esbranquiçada.

Élitros castanho-amarelados revestidos por pubescência amarelada; duas faixas transversais, em zigue-zague, de pubescência esbranquiçada, com pelos mais longos e concentrados num tufo largo: uma no quarto apical e outra ante- 
apical. Mancha circular castanha no dorso dos élitros, logo atrás do meio.

Material examinado. BRASIL, Bahia: Encruzilhada (15'32’25'S, 4050'12'W, 800m), macho, 10-12.XII.2007, J. A. Rafael, P. C. Grossi \& D. R. Parizotto col., armadilha luminosa (INPA).

\section{Cotycicuiara magnifica sp. nov.}

(Fig. 6)

Etimologia. Latim, magnificus = magnífico, esplendido, alusivo ao belo colorido.

Tegumento castanho-avermelhado. Cabeça revestida por pubescência amarelada. Fronte muito estreita. Lobos oculares superiores dão distantes entre si quanto duas fileiras de omatídios. Lobos oculares inferiores ocupam quase todo o lado da cabeça. Antenas atingem o ápice elitral no meio do antenômero IX. Escapo cilíndrico, comprimento subigual ao do III. Antenômeros IV-XI com comprimentos gradualmente decrescentes.

Lados do protórax com gibosidade projetada e arredondada no ápice no nível do terço posterior; revestido por pubescência amarelo-alaranjada; setas longas atrás da gibosidade. Pronoto com pontos grossos, moderadamente esparsos. Esternos torácicos revestidos por pubescência amarelo-alaranjada; metepisterno e lados do metasterno com mancha de pubescência branca, compacta; terço posterior do metasterno, a cada lado da sutura metasternal, manchas triangular de pubescência castanho-escura.

Élitros revestidos por pubescência amarelo-alaranjada; faixa larga, transversal, de pubescência esbranquiçada, compacta, na região centro-anterior do élitro, da margem a sutura; na margem, prolongada anterior e posteriormente; borda anterior da área branca, oblíqua em sentido descendente da margem para a sutura; terço apical com faixa transversal, mais estreita e bordas irregulares; entre as faixas, duas pequenas manchas longitudinais de pubescência esbranquiçada. Pontuação elitral fina, mais concentrada no terço basal e mais esparsa em direção ao ápice.

Pernas com pubescência fina, amarelo-acastanhada.

Urosternitos com pubescência amarelo-acastanhada no centro e preta nos lados.

Dimensões em mm. Comprimento total, 11,8; comprimento do protórax, 2,4; maior largura do protórax, 3,9; comprimento do élitro, 8,5; largura umeral, 4,7.

Material-tipo. Holótipo macho, BRASIL, Amazonas: Manaus (ZF2 km 14, Torre, 40 m, 0335'21' S, 6006'55’ W), 19-22.III.2004, J. A. Rafael, C. S. Motta. F. F. Xavier F ${ }^{o}$ \& J. T. Câmara col., lençol: luz mista e BL/BLB (INPA).

Discussão. Cotycicuiara magnifica sp. nov. distingue-se de todas as espécies pelo padrão de colorido dos élitros e pelas manchas pretas do metasterno e dos lados dos urosternitos. Diferencia-se de C. pertusa Martins \& Galileo, 2010, pela faixa de pubescência branca transversal sem pontos grandes contrastantes.

\section{Cyrtinini \\ Omosarotes paradoxum (Tippmann, 1955)}

(Fig. 5)

Acanthomerosternoplon paradoxum Tippmann, 1955: 12.

Omosarotes paradoxum; Julio \& Monné 2001: 104; Monné 2005: 311 (cat.). Cyrtinacantha mirabilis Zajciw, 1970: 350.

A espécie foi descrita originalmente do Peru, Rio Perené. Zajciw (1970) registrou para Peru (Junin), Julio \& Monné (2001) acrescentaram Equador (Napo) e Brasil (Amazonas e Rondônia). Assinalamos a espécie para o Pará (Brasil).

Dimensões em mm. Comprimento total, 5,5; comprimento do protórax, 1,3; maior largura do protórax (espinho inclusive), 1,5, comprimento do élitro, 3,6; largura umeral, 1,5.

Material-examinado. BRASIL, Pará: Tucuruí (próximo à barragem), fêmea, 2.XII.2001, J. A. Rafael \& J. F. Vidal col., Malaise (INPA).

\section{Acanthoderini}

\section{Ozotroctes ogeri Tavakilian \& Néouze, 2007}

Ozotroctes ogeri Tavakilian \& Néouze, 2007: 4.

Espécie baseada em único exemplar procedente da Guiana Francesa, Piste de Kaw ( $\mathrm{km} \mathrm{33,5).} \mathrm{O} \mathrm{material} \mathrm{examinado}$ permite registrá-la para o Brasil.

Material examinado. Amazonas: Barcelos (Rio Demeni, 0¹8'05'S, $62^{\circ} 45^{\prime} 56^{\prime}$ W), macho, VIII.2008, A. Filho \& R. Machado col., na luz, no barco (INPA).

\section{AGRADECIMENTOS}

Aos pesquisadores do Instituto Nacional de Pesquisas da Amazônia, José Albertino Rafael e Augusto Henriques pela calorosa acolhida durante a visita a Manaus. A Eleandro Moysés (bolsista PIBIC/CNPq/FZB) pela execução e tratamento das fotografias. Ao CNPq e FAPEAM pelo auxílio financeiro ao Programa de Apoio a Núcleos de Excelência (Pronex) projeto 'Amazonas: diversidade de insetos ao longo de suas fronteiras (Processo 1437/207)' coordenado por José Albertino Rafael (INPA).

\section{REFERÊNCIAS}

Aurivillius, C. 1900. Verzeichniss der von Dr. F. Meinert im Jahre 1891 in Venezuela gesammelten Cerambyciden. Öfversigt VetenskapsAkademiens Föhandlingar 57: 409-421.

Aurivillius, C. 1912. Coleopterorum Catalogus, pars 39, Cerambycidae: Cerambycinae. Berlin, W. Junk, 574 p.

Bates, H. W. 1885. Biologia Centrali-Americana, Insecta; Coleoptera, suppl. to Longicornia, London. v. 5, p. 249-436.

Chemsak, J. A.; E. G. Linsley \& F. A. Noguera. 1992. Listados Faunísticos de México II. Los Cerambycidae y Disteniidae de Norteamérica, Centroamérica y las Indias Occidentales. México, Univ. Nac. Autónoma de México, Instituto de Biología, 204 p.

Galileo, M. H. M. \& U. R. Martins. 2003. Novos táxons neotropicais de Desmiphorini (Lamiinae). Iheringia, série Zoologia 93: 159-166. 
Galileo, M. H. M. \& U. R. Martins. 2008. Novo gênero de Desmiphorini com cinco espécies novas (Coleoptera, Cerambycidae, Lamiinae). Les Cahiers Magellanes 83: 1-10.

Julio, C. E. A. \& M. A. Monné. 2001. Sinopse dos gêneros Scopadus e Omosarotes (Cyrtinini). Iheringia, série Zoologia 91: 101-107.

Joly, L. J. 1991. Sinopsis de la tribu Ibidionini en Venezuela. Acta Terramaris 4: $1-84$.

Linsley, E. G. 1935. Notes and descriptions of new or little known neotropical Ibidionini. Revista de Entomologia 5: 479-486.

Martins, U. R. 1960. Ibidionini V. Comentários e descrição de novas espécies do gênero Gnomidolon Thomson. Papéis Avulsos de Zoologia 14: $1-10$.

Martins, U. R. 1967. Monografia da tribo Ibidionini. Parte I. Arquivos de Zoologia 16: 1-320.

Martins, U. R. 1971a. Monografia da tribo Ibidionini. Parte VI. Arquivos de Zoologia 16: 1343-1508.

Martins, U. R. 1971b. Notas sobre Cerambycinae VI. Subsídios ao conhecimento dos Ibidionini. Arquivos de Zoologia 21: 121-178.

Martins, U. R. 2006. Tribo Hexoplonini, p. 21-211. In: Cerambycidae sulamericanos (Coleoptera). v. 8, São Paulo, Sociedade Brasileira de Entomologia, 234 p.

Martins, U. R. 2009. Tribo Ibidionini. Subtribo Compsina, p. 1-199. In:
Cerambycidae sul-americanos (Coleoptera). v. 10, São Paulo, Sociedade Brasileira de Entomologia, 373 p.

Martins, U. R. \& M. H. M. Galileo. 2007. Tribo Ibidionini. Subtribo Tropidina, p. 1-176. In: Cerambycidae sul-americanos (Coleoptera). v. 9, São Paulo, Sociedade Brasileira de Entomologia, 349 p.

Martins, U. R. \& M. H. M. Galileo. 2010. New species of the genus Cotycicuiara Galileo \& Martins, 2008 (Cerambycidae, Lamiinae, Desmiphorini). Insecta Mundi 134: 1-6.

Monné, M. A. 2005. Catalogue of the Cerambycidae (Coleoptera) of the Neotropical region. Part I. Subfamily Cerambycinae. Zootaxa 946: 1765 .

Tavakilian, G. L. \& G.-L. Néouze. 2007. Le genre Ozotroctes Bates: nouvelles espèces et nouveaux genres apparentés d'Acanthoderini (Coleoptera, Cerambycidae, Lamiinae). Coléoptères 13: 1-24.

Thomson, J. 1867. Ibidionitarum species novae. Physis Recueil d'Histoire Naturelle 1: 133-163.

Tippmann, F. F. 1955. Eine neue morphologisch einmalige Lamiine aus OstPeru (Coleoptera, Cerambycidae, subfam. Lamiinae). Entomologische Blatter 51: 8-14.

Zajciw, D. 1970. Um gênero e duas espécies novas da tribo Cyrtinini da América do Sul (Coleoptera, Cerambycidae, Lamiinae). Studia Entomológica 13: 345-352. 